\title{
Sequential dual curing by selective Michael addition and free radical polymerization of acetoacetate-acrylate-methacrylate mixtures
}

\author{
Ali Osman Konuray a , Anna Ruiz ${ }^{a}$, José M. Morancho ${ }^{a}$, José M. Salla ${ }^{a}$, Xavier Fernández-Francos ${ }^{\mathrm{a}}$, \\ Àngels Serra ${ }^{\mathrm{b}}$, Xavier Ramisa, ${ }^{\mathrm{a}}$, \\ a Thermodynamics Laboratory, ETSEIB Universitat Politècnica de Catalunya, Av. Diagonal 647, 08028 Barcelona, Spain \\ ${ }^{\mathrm{b}}$ Department of Analytical and Organic Chemistry, Universitat Rovira i Virgili, C/ Marcel-lí Domingo s/n, Edifici N4, 43007 Tarragona, Spain
}

\section{A R T I C L E IN F O}

\section{Keywords:}

Michael addition

Acetoacetate

Acrylates

Free-radical polymerization

Thermosets

\begin{abstract}
A B S T R A C T
A new family of poly(keto ester)-poly(methacrylate) thermosets based on off-stoichiometric acetoacetate-acrylate/methacrylate formulations has been prepared and characterized. The first stage of curing is a self-limiting click Michael addition between acetoacetate and acrylate groups at room temperature and the second stage is a methacrylate radical photopolymerization.

An analysis of the reaction kinetics confirmed that acetoacetate reacts selectively with acrylates, leaving methacrylates completely unreacted after the first curing stage. It was found that acrylate-rich mixtures achieve complete conversion at the end of both curing stages. In methacrylate-rich formulations the dilution effect of this monomer leads to a slow curing rate and a certain amount of unreacted acrylates in the first curing stage, which react completely after irradiation in the second curing stage.

The prepared materials are gelled after acetoacetate/acrylate Michael addition and show a wide range of properties at both curing stages that can be tailored by changing the relative contribution of the Michael and radical vinyl homopolymerization reactions. The latency of the formulations at the beginning of the second stage can be regulated as desired by irradiation.
\end{abstract}

\section{Introduction}

Custom-tailored thermosets can be obtained by dual curing procedures, combining two different and compatible polymerization reactions. Although these reactions can take place sequentially or simultaneously, sequential dual curing represents significant advantages in terms of control of the process and the formed network. Concretely, sequential strategy enables the preparation of easily-handled materials with high latency after a first stage of curing which, upon the application of a second stimulus, further crosslink to achieve the ultimate properties [1].

Click polymerization reactions are a prized tool for sequential dual curing processing because of their efficiency, selectivity, orthogonality and absence of by-products. Michael addition reactions are attracting interest in the recent years due to

\footnotetext{
* Corresponding author.

Email address: ramis@mmt.upc.edu (X. Ramis)
} 
their versatility in terms of monomer selection, low VOCs emissions, and reaction temperature, which make it possible to prepare thermosets under conditions where other reactions would be impossible [2,3].

Two strategies for the preparation of click dual-cured thermosets can be highlighted. Firstly, the combination of two click reactions [4-9] for both curing stages and secondly, the combination of a click reaction with another polymerization reaction that takes place in different conditions and usually through a different reaction mechanism (e.g. step-growth followed by chain-growth) [10-14]. Networks obtained via step-growth polymerization reactions have remarkable features in comparison with those obtained via chain-growth polymerization reactions: higher homogeneity, high capacity for mechanical energy absorption near its glass transition temperature, high conversion at the gelation and low polymerization-induced shrinkage stress [2].

Using this strategy, several authors have prepared dual-cured thermosets from off-stoichiometric formulations such as acetoacetate-acrylate, amine-acrylate or thiol-acrylate [15-17]. The first stage reaction is a self-limiting Michael addition between multifunctional Michael donor (amine, thiol or acetoacetate) and Michael acceptor (acrylate monomers) with an excess of acrylate groups. The second stage reaction is a photo-induced radical polymerization of the unreacted acrylate groups. In general, all systems prepared by this strategy, reach practically complete conversions of all reactive species at the end of the second stage. Moreover, the resulting materials exhibit a wide array of properties, making most of these systems easily adaptable to different application demands such as shape memory polymers, printing materials, and optical materials for writing refractive index patterns [6,15-19]. The properties of the intermediate and final materials can be further refined by replacement of the excess of acrylate monomers by methacrylate monomers. Due to the inductive effect of the methyl group in the methacrylate and to the steric hindrance caused by the methyl in $\alpha$ position, methacrylates are poor Michael acceptors. As a result, they barely react via Michael addition and participate preferably in homopolymerization reactions, and this selectivity can be useful for the design of new dual-curing systems.

Acetoacetate-acrylate Michael addition chemistry is frequently used in organic synthesis and in the preparation of acetoacetate-functional monomers for different applications such as low energy curing coatings and adhesives [3,20-28], but only few works deal on free-solvent dual-curing thermosets where at least one curing stage is a $\beta$-ketoester-acrylate Michael addition [11,17,29]. This fact is probably due to the difficulty of achieving complete cure, the inferior thermomechanical properties of the prepared materials and to the existence of only a few commercially available acetoacetates. Incomplete acetoacetate final conversion can be explained by the low reactivity of the carbanion formed after extraction of the second acetoacetate hydrogen $\left(p \mathrm{Ka}_{1}=12, p \mathrm{Ka}_{2}=13\right)[26]$, and the topological restrictions that reduce its nucleophilic character. These restrictions can be due to the effect exerted by the substituent on the formed monoadduct and to the strongly hindered network structure formed when a multifunctional acetoacetate of low equivalent weight is used. Increasing the length of the spacer between acetoacetate groups in the monomer and the use of an excess of Michael acceptor favours a higher acrylate conversion, but at the same time, it can reduce the glass transition temperature and the elastic modulus of the cured material [17]. An adequate selection of monomers, catalysts, curing conditions and the relative contribution of both curing stages in dual-curing systems can avoid some of these drawbacks. The mechanism of a thermosetting acrylic network building, such as poly(acrylate)s and poly(methacrylate)s, generally leads to the formation of heterogeneous structures with unreacted double bonds even after postcuring [30]. Therefore, the addition of a reactive or non-reactive diluent or a second flexible structure as the one formed in Michael additions [16,17], can favour the formation of a more homogeneous structure with no unreacted double bonds remaining.

Taking all of this into account, in the present publication, we report the preparation and characterization of new thermosets using a solvent-free dual curing scheme carried out at near-ambient conditions. Acetoacetate-acrylate stoichiometric mixtures with an excess of methacrylate monomers were dual-cured by a sequential process consisting of base-catalyzed Michael addition of acetoacetates to acrylates followed by the photoinitiated free radical polymerization of the methacrylate groups and the unreacted acrylate groups. The employed dual curing methodology is depicted in Scheme 1.

The new materials are based exclusively on available commercially acrylates, methacrylates and a trifunctional acetoacetate, named K-FLEX ${ }^{\mathrm{TM}} 7301$ marketed as a low viscosity reactive diluent, that can be crosslinked with amino resins, polyisocyanates, polyamides, polyamines and unsaturated polymers.

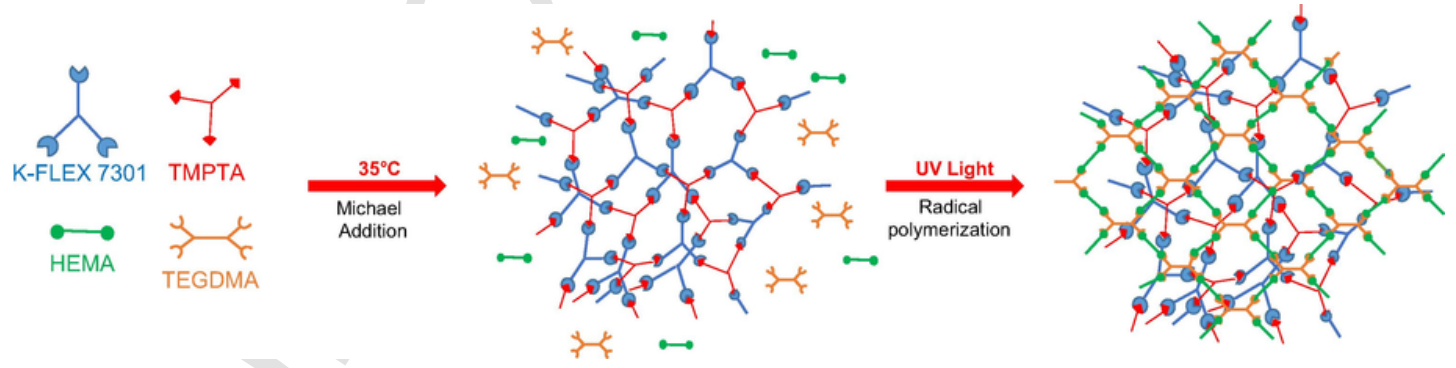

Scheme 1. Schematic representation of the dual curing methodology. In order to gain clarity the homopolymerization of HEMA and TEGDMA has not been included. 
First of all we characterized K-FLEX ${ }^{\mathrm{TM}} 7301$ and its functionality, and studied the influence of the amount of catalyst, 1,5-diazabicycle[4.3.0]non-5-ene, on the kinetics of first curing stage, by means of calorimetry and FTIR. We then analyzed the effect of the composition of the formulation (i.e. relative acetoacetate/acrylate and methacrylate content) on the reaction kinetics and on the thermal and viscoelastic properties of materials both at the intermediate (i.e. after Michael addition) and final stage (i.e. after photopolymerization). The kinetics of both curing stages and the conversion reached at completion of cure were studied by FTIR spectroscopy, and the gelation during Michael addition was studied by thermomechanical analysis. The materials obtained were characterized by calorimetric, dynamomechanical and thermogravimetric analyses.

The resulting materials exhibit a wide array of properties depending on the relative contribution of both curing stages and on the structure of the monomers, making them custom-tailorable and adaptable to a wide array of processing and application requirements. Complete reaction of all acrylate and methacrylate groups at the end of the second curing stage was achieved. All materials were stable after Michael addition and can be safely stored before further processing in a second step.

\section{Materials and methods}

\subsection{Materials}

All chemicals and reagents were purchased from Sigma-Aldrich and used as received unless noted otherwise. Trifunctional trimethylolpropane triacrylate (TMPTA, $M_{w}=296.3 \mathrm{~g} / \mathrm{mol}$ ) was used as base acrylate monomer. A mixture of $75 \%$ by weight of hydroxyethyl methacrylate (HEMA, $M_{w}=130.14 \mathrm{~g} / \mathrm{mol}$ ) and $25 \%$ by weight of triethylene glycol dimethacrylate (TEGDMA, $M_{w}=286.3 \mathrm{~g} / \mathrm{mol}$ ) was used as base methacrylate. This mixture (hereafter referred to as HT), rich in HEMA, was selected to facilitate higher conversions in methacrylate photopolymerization and to achieve the ultimate desired glass transition temperature. A trifunctional acetoacetate K-FLEX ${ }^{\mathrm{TM}} 7301$ (hereafter referred to as KF, equivalent weight per active hydrogen of $125 \mathrm{~g} / \mathrm{e}$ according to the data sheet), supplied by King Industries, was used as Michael reagent donor. This product was identified by $\mathrm{H}^{1}$ NMR as highly pure trimethylolpropane triacetoacetate (see Fig. 1).

${ }^{1} \mathrm{H}$ NMR (400 MHz, $\mathrm{CDCl}_{3}, \delta$ en ppm): 0.87 (t, 3H, $\mathrm{CH}_{2} \mathrm{CH}_{3}$ ), 1.47 (q, 2H, $\mathrm{CH}_{3} \mathrm{CH}_{2}$ ), 2.25 (s, 9H, COCH ) $_{3.48}(\mathrm{~s}, 6 \mathrm{H}, \mathrm{COCH} \mathrm{CO})$ and $4.06\left(\mathrm{~s}, 6 \mathrm{H}, \mathrm{COOCH}_{2}\right)$.

Dimethoxy-2-phenylacetophenone (DMPA) and 1,5-diazabicycle[4.3.0]non-5-ene (DBN) $(p K a=13.5)$ [31] were used as photoinitiator and catalytic system for Michael addition reactions, respectively. Scheme 2 shows the chemical structure of the compounds used.<smiles>CCC(COC(=O)CC(C)=O)(COC(=O)CC(C)=O)C(=O)S</smiles>

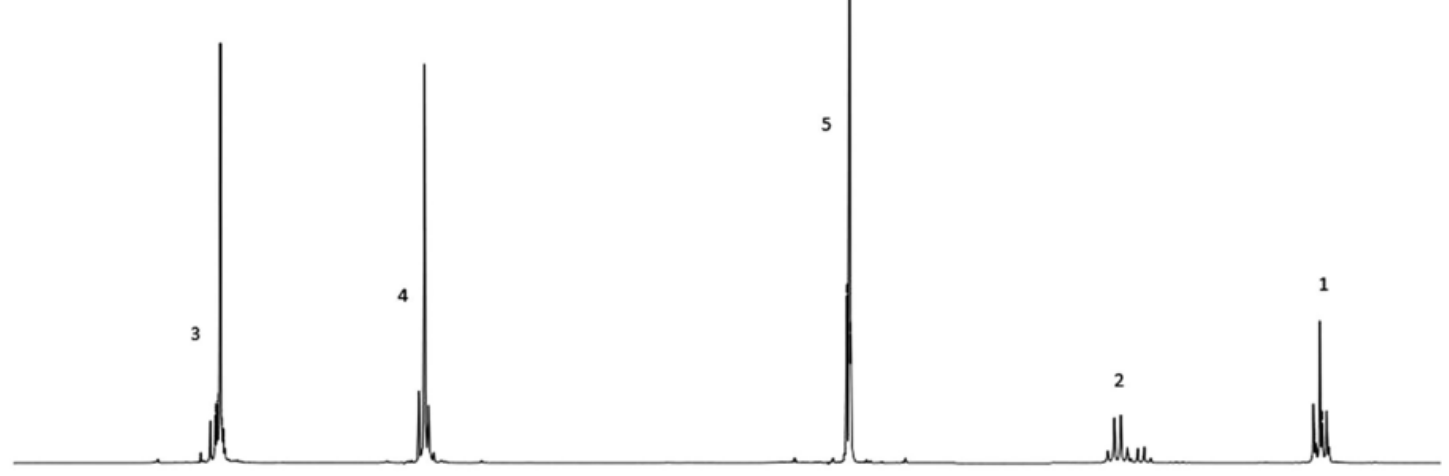

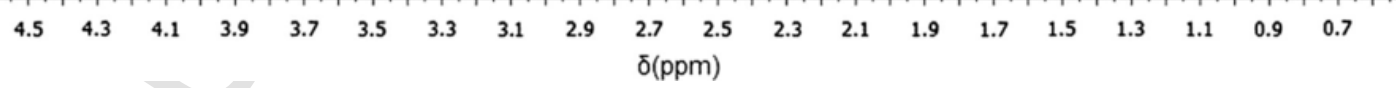

Fig. 1. ${ }^{1} \mathrm{H}$ NMR spectrum of K-FLEX ${ }^{\mathrm{TM}} 7301$ in $\mathrm{CDCl}_{3}$. 
<smiles>CC(=O)CC(=O)OCC(C)(COC(C)=O)COC(=O)CC(C)=O</smiles>

F-FLEX 7301<smiles>C=C(C)C(=O)OCCOCCOCCOC(=O)C(=C)C</smiles><smiles>C1CN=C2CCCN2C1</smiles>

DBN<smiles>C=CC(=O)OCC(C)(COC(=O)C=C)COC(=O)C=C</smiles>

TMPTA<smiles>C=C(C)C(=O)OCCO</smiles>

HEMA

Scheme 2. Molecular structures of the chemicals used.

\subsection{Sample preparation}

DBN ( $1 \%$ in parts per hundred of the total reactive mixture) was added to acetoacetate and stirred mechanically for 5 min at room temperature and the mixture was allowed to equilibrate for $60 \mathrm{~min}$ at $35^{\circ} \mathrm{C}$. Methacrylate formulations were prepared by first mixing TEGDMA and HEMA and finally a 2\% DMPA (in parts per hundred of the methacrylate mixture) was added, followed by mechanically stirring until the mixture became clear at room temperature and then methacrylate mixture was added to the acetoacetate/DBN mixture. Finally, the required amount of TMPTA was added followed by quick stirring and immediate analysis or sample preparation. To prevent premature polymerization, during the addition of TMPTA the mixture was immersed in an ice bath.

Different formulations were prepared and coded as KFx_TMPTAy_HTz where $x, y$, and $z$ stand for molar equivalents of acetoacetate active protons, acrylate double bonds and methacrylate double bonds, respectively. All formulations contained stoichiometric amounts FK and TMPTA (being $x=1$ and $y=1$ ) and a variable excess of methacrylate groups.

Fully cured samples for dynamic mechanical analysis and thermal analysis assays were prepared in a polypropylene mold with dimensions ca. $1 \times 13 \times 20 \mathrm{~mm}^{3}$. The liquid formulations were poured into the mold and kept in an oven at a controlled temperature of $35^{\circ} \mathrm{C}$ to carry out the acetoacetate-acrylate Michael reaction until the conversion plateau was reached. The samples were subsequently irradiated at room temperature in a Vilber Lourmat UV oven equipped with 6 lamps emitting UV light at a wavelength of $365 \mathrm{~nm}$ and $4 \mathrm{~mW} / \mathrm{cm}^{2}$ total light intensity. The samples were irradiated on both sides, and received a total dose of $20.1 \mathrm{~J} / \mathrm{cm}^{2}$. A thermal postcuring was carried out for $1 \mathrm{~h}$ at $120^{\circ} \mathrm{C}$ in order to overcome vitrification limitations, especially in methacrylate rich-formulations. Longer curing times in stage 1 were tested, but the curing process did not advance significantly.

\subsection{Monitoring of the curing process}

A Brucker Vertex 70 FTIR spectrometer equipped with an attenuated total refection (ATR) accessory (Golden gateTM, Specac Ltd.) which is temperature controlled (heated single-reflection diamond ATR crystal) was used to monitor the evolution of acrylate/ methacrylate groups during the isothermal dual curing at $35^{\circ} \mathrm{C}$ of the formulations. Real-time spectra were collected at $35^{\circ} \mathrm{C}$ in absorbance mode with a resolution of $4 \mathrm{~cm}^{-1}$ and a wavelength range from 400 to $4000 \mathrm{~cm}^{-1}$, averaging 20 scans for each spectrum. A Hamamatsu Lightningcure LC5 (Hg-Xe lamp) with one beam conveniently adapted to ATR accessory was used to irradiate the samples during the second curing stage. The irradiation intensity was $17 \mathrm{~mW} / \mathrm{cm}^{2}$ (measured at $365 \mathrm{~nm}$ ). To prevent the inhibitory effect of oxygen during free radical photopolymerization and to homogenize the sample, a drop of sample was covered with polypropylene film, prior to UV-irradiation. The dual curing process was performed in a similar way to the sample preparation described above. The first curing stage was carried out without irradiation until maximum acrylate conversion was achieved, followed by 5 min of UV-irradiation (second stage). It was observed that final acrylate/methacrylate conversion did not change when irradiation was carried out for longer durations. Spectra were continuously recorded during first and second stage. A neat methacrylate formulation was also photocured for comparison purposes.

The spectra were corrected taken into account the dependence of the penetration on the wavelength and normalized using the area of the carbonyl ester band at $1716 \mathrm{~cm}^{-1}$. The absorption peaks at $808 \mathrm{~cm}^{-1}$ and $816 \mathrm{~cm}^{-1}(\mathrm{C}=\mathrm{C}$ deformation) 
were used for the monitoring of acrylate and methacrylate conversion, respectively [20]. The conversion of double bonds is denoted as $\alpha$ and it is defined by Eq. (1).

$\alpha=1-\frac{A_{t}^{\prime}}{A_{0}^{\prime}}$

where $A^{\prime}$ is the normalized area of the acrylate or methacrylate bands, and the subscripts $t$ and 0 indicate the curing time and the beginning of the curing, respectively. The analysis of the absorption peaks of interest were carried out using the OPUS Spectroscopy Software version 6.5 (Brucker Optics). The peak at $1407 \mathrm{~cm}^{-1}\left(\mathrm{CH}_{2}\right.$ scissor deformation mode of acrylate) and the peak at the band $1306-1320 \mathrm{~cm}^{-1}(\mathrm{C}-\mathrm{O}-\mathrm{C}$ stretching vibration of methacrylate) were also used to confirm qualitatively the evolution of the curing. The conversion of acetoacetate in the first stage can be considered proportional to acrylate conversion during this stage, since methacrylate are not able to react with acetoacetate and each acrylate reacts with one $\mathrm{C}-\mathrm{H}$ group of acetoacetate during Michael addition.

\subsection{Gelation}

A Mettler thermo-mechanical analyzer SDTA840 was used to determine the gel point during Michael addition (first stage). A silanized glass fiber disc about $5 \mathrm{~mm}$ in diameter was impregnated with the liquid (uncured) formulation and sandwiched between two aluminium discs. The sample was placed at $35^{\circ} \mathrm{C}$ for different times and subjected to an oscillatory force from 0.005 to $0.1 \mathrm{~N}$ with an oscillation frequency of $0.083 \mathrm{~Hz}$. The gel time, $t_{g e l}$, was taken as the onset in the decrease of the oscillation amplitude measured by the probe. The conversion of acrylate groups at the gel point, $\alpha_{g e l}$ was determined as the conversion reached in the FTIR at the gel time.

The theoretical conversion of acrylate groups at the gel point, $\alpha_{g e l}$, during Michael reaction (stage 1) was calculated assuming ideal random step-wise reaction, using the well-known Flory-Stockmayer equation [12,34]:

$\alpha_{g e l}^{\text {theor }}=\frac{1}{\sqrt{r(f-1)(g-1)}}$

where $r$ is the acrylate/acetoacetate equivalent ratio, $f$ the acetoacetate functionality and $g$ the acrylate functionality. For all our systems $r, f$ and $g$ were 1,3 and 3 , respectively.

\subsection{Differential scanning calorimetry (DSC)}

To determine glass transition temperatures $\left(T_{g} \mathrm{~s}\right)$ of the obtained materials at intermediate and final (after postcuring) stages, analyses were carried out on a Mettler DSC822e thermal analyzer. The DSC822e analyzer was calibrated using an indium standard (heat flow calibration). Samples of approximately $10 \mathrm{mg}$ were placed in aluminium pans with pierced lids and analyzed by choosing a temperature ramp of $10^{\circ} \mathrm{C} / \mathrm{min}$ from $-100^{\circ} \mathrm{C}$ to $250^{\circ} \mathrm{C}$ under $\mathrm{N}_{2}$ atmosphere. $T_{g}$ s were determined as the temperature of the half-way point of the jump in the heat capacity $\left(\Delta C_{p}\right)$ when the material changed from glassy to the rubbery state under $\mathrm{N}_{2}$ atmosphere and the error is estimated to be approximately $\pm 1^{\circ} \mathrm{C} . \Delta C_{p}$ 's of intermediate and final materials were also measured.

The curing of KF_1_TMPTA1_HT0 formulations containing different amounts of catalyst were also studied by DSC. Samples were cured at a constant heating rate of $10^{\circ} \mathrm{C} / \mathrm{min}$ and the degree of conversion at a given temperature $T$ was calculated as the ratio between the heat released up to $T$ and the total reaction heat associated with complete conversion of all reactive groups.

\subsection{Dynamic mechanical analysis (DMA)}

Fully-cured materials were analyzed using a TA Instruments DMA Q800 device. Prismatic rectangular samples $\left(\right.$ ca. $1 \times 13 \times 20 \mathrm{~mm}^{3}$ ) were analyzed by DMA using a single cantilever clamp at a frequency of $1 \mathrm{~Hz}$ and $0.05 \%$ strain at $3{ }^{\circ} \mathrm{C} / \mathrm{min}$ from $-50{ }^{\circ} \mathrm{C}$ up to a temperature sufficiently high for complete network relaxation. The peak temperatures of $\tan \delta$ curves were taken as $\alpha$-relaxation temperatures, related with the glass transition temperatures.

\subsection{Thermogravimetric analysis (TGA)}

Thermogravimetric analysis was carried out with a Mettler TGA/SDTA 851e/LF/1100 thermobalance. Samples, obtained by dual curing, with an approximate mass of $10 \mathrm{mg}$ were degraded between 30 and $800^{\circ} \mathrm{C}$ at a heating rate of $10^{\circ} \mathrm{C} / \mathrm{min}$ in $\mathrm{N}_{2}$ atmosphere $\left(50 \mathrm{~cm}^{3} / \mathrm{min}\right.$ measured in normal conditions). 


\subsection{NMR characterization}

${ }^{1} \mathrm{H}$ spectrum was registered in a Varian Gemini 400 spectrometer. $\mathrm{CDCl}_{3}$ was used as the solvent. For internal calibration, the solvent signal corresponding to $\mathrm{CDCl}_{3}$ was used: $\delta(1 \mathrm{H})=7.26 \mathrm{ppm}$.

\section{Results and discussion}

\subsection{Preliminary results}

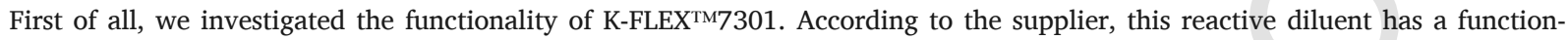
ality of 3, although K-FLEX ${ }^{\mathrm{TM}} 7301$ has three acetoacetate groups containing two acidic protons each, that can potentially undergo Michael addition. Stoichiometric formulations KF1_TMPTA1_HT0 containing $1 \%$ of DBN were isothermally cured at $80^{\circ} \mathrm{C}$ considering the functionality of K-FLEX ${ }^{\text {TM73 }} 301$ as 3 and 6 . The materials obtained reached an ultimate $T_{g}$ of $24^{\circ} \mathrm{C}$ and $76^{\circ} \mathrm{C}$ and an acrylate conversion of $98 \%$ and $79 \%$, respectively. Moreover, when a functionality of 6 was considered, the kinetics of the reaction became much slower, especially at conversions above $50 \%$. These results suggest that more than 3 carbon positions are available to react by Michael addition, but a significant portion of them cannot react even after long curing times. This behavior is probably due to the steric hindrance created by the Michael acceptor covalently linked to the acetoacetate. Once the first methylene carbon reacts, its nucleophilicity reduces. In addition, the lower acidity of the second proton on the methylene acetoacetate group reduces the amount of carbanion capable to attack the Michael acceptor [26]. In order to ensure that acrylate groups achieve a maximum conversion and to better control the stoichiometry of the reaction, K-FLEX ${ }^{\mathrm{TM}} 7301$ was assumed to be a trifunctional monomer. Therefore, it is expected that all the methylene carbons on acetoacetate can react only once with acrylate monomers during first curing stage.

The selection of the amount and type of catalyst was performed according to the $p$ Ka values of the methylene groups in the acetoacetate and different bases. In a previous manuscript [29] it was found that $2 \%$ of DBN ( $p$ Ka $=13.5$ ) [31] was sufficient for a stoichiometric mixture of diethyl 3-oxopentanedionate (difunctional acetoacetate) and TMPTA to completely react after $12 \mathrm{~h}$ at $80^{\circ} \mathrm{C}$ followed by a postcuring for $30 \mathrm{~min}$ at $200^{\circ} \mathrm{C}$. Because the acidity of the methylene protons on diethyl 3-oxopentanedionate seems significantly different from those of K-FLEX ${ }^{\mathrm{TM}} 7301$, stoichiometric KF1_TMPTA1_HT0 formulations containing different amounts of DBN, were non-isothermally cured in the DSC at $10^{\circ} \mathrm{C} / \mathrm{min}$. Fig. 2 shows heat flows and conversions plotted against temperature and the heat released per double bond. On increasing the DBN content, the reaction heat remains almost constant $(53-61 \mathrm{~kJ} / \mathrm{mol} \mathrm{C}=\mathrm{C})$ and similar to the values reported for the polymerization of similar acrylates $[35,36]$. This result, along with the fact that FTIR spectra of the samples after DSC curing do not show traces of the $\mathrm{C}=\mathrm{C}$ acrylate deformation band at $808 \mathrm{~cm}^{-1}$, indicates that all mixtures reacted almost completely. It can also be observed that the curing of the mixture with $2 \%$ of DBN started below room temperature, so that some of the reaction heat might have been lost during mixing and sample preparation, hence the lower reaction heat detected. In formulations containing a $0.5 \%$ and a $1 \%$ of $\mathrm{DBN}$, the reaction starts near room temperature, but the formulation containing $0.5 \%$ DBN reaches complete curing only at higher temperatures. KF1_TMPTA1_HT0 mixture containing 1\% of DBN was isothermally cured at $35^{\circ} \mathrm{C}$ and monitored by FTIR, reaching nearly complete conversion in $7 \mathrm{~h}$. It was also observed that the mixture without catalyst could also react, but at extremely high temperatures. Taking into account all these results, $1 \%$ DBN was selected as the catalytic system and $35^{\circ} \mathrm{C}$ as the curing temperature for our study.
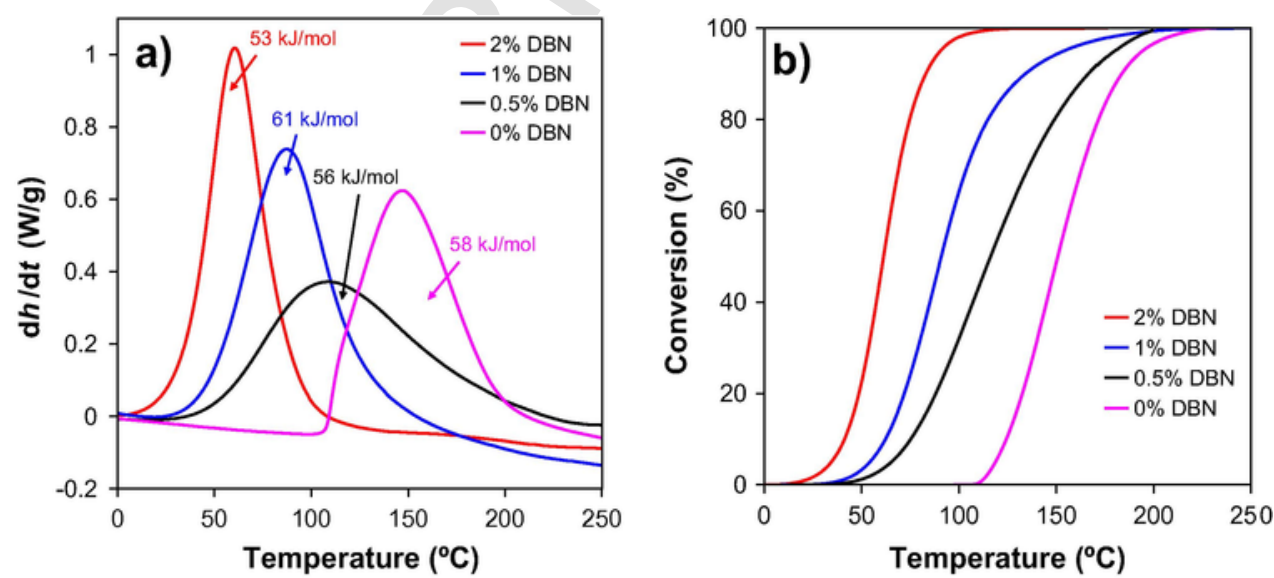

Fig. 2. DSC thermograms (a) and conversions (b) plotted against temperature for KF 1 _TMPTA1_HT0 with $0 \%, 0.5 \%, 1 \%$ and $2 \%$ of the DBN at a heating rate of $10{ }^{\circ} \mathrm{C} /$ min. Reaction heats in $\mathrm{kJ} /$ moles of $\mathrm{C}-\mathrm{C}$ double bonds are also indicated in figure a. (For interpretation of the references to colour in this figure legend, the reader is referred to the web version of this article.) 
The choice of the methacrylate mixture, HEMA/TEGDMA, was based on preliminary experimental work (not shown in this paper) and on previous results $[12,16]$. HEMA was selected as a reactive diluent to facilitate higher conversions in methacrylate photopolymerization and TEGDMA because it leads to highly rigid materials. HEMA/TEGDMA formulations with different amounts of both monomers were photocured and characterized. The $T_{g}$ increases with increasing HEMA content and takes the following values: $100{ }^{\circ} \mathrm{C}$, $110^{\circ} \mathrm{C}$ and $120^{\circ} \mathrm{C}$ for 25\%HEMA/75\%TEGDMA, 50\%HEMA/50\%TEGDMA and 75\%HEMA/25\%TEGDMA formulations, respectively. Because it gives the highest $T_{g}$, the formulation containing $75 \%$ by weight of HEMA and $25 \%$ by weight of TEGDMA (hereafter referred to as HT), was chosen as methacrylate monomer. This mixture has an average functionality of 2.26 in free radical polymerization (calculated by taking into account the mixture composition and the functionality of HEMA and TEGDMA, which are 2 and 4 , respectively).

\subsection{Dual curing and properties of acetoacetate/acrylate/methacrylate mixtures}

Acetoacetate-acrylate-methacrylate polymers consisting of KF/TMPTA stoichiometric mixtures with an excess of HT methacrylate were chosen to demonstrate the potential value of the dual cure Michael reaction/free radical polymerization to prepare tailor-made materials, storable and processable after the first curing step and with a broad range of properties after completion of the second curing process. Table 1 summarizes the composition and functionality of the formulations used in this work and acrylate conversions and glass transition temperatures after both curing stages.

The acetoacetate/acrylate Michael addition and methacrylate homopolymerization was monitored with FTIR at $35^{\circ} \mathrm{C}$. Figs. 3 and 4 show some spectra collected during reaction of formulation KF1_TMPTA1_HT1. In Fig. 3 it can be observed how the absorbance of the peaks in the region between 770 and $840 \mathrm{~cm}^{-1}$ decreases during the curing process. To investigate the extent of the selectivity of the Michael reaction towards acrylates, for each formulation, acrylate and methacrylate conversions were determined from the $808 \mathrm{~cm}^{-1}$ and $816 \mathrm{~cm}^{-1}$ absorption peaks, respectively. These peaks were identified using the spectra of neat acrylate and methacrylate mixture, showed in Fig. 3 as coloured dashed lines. Conversions were determined using Eq. (1) after deconvolution of the broad band at $812 \mathrm{~cm}^{-1}$, which includes overlapping acrylate and methacry-

Table 1

Composition and average functionalities of formulations studied in this work. Acrylate conversions, $T_{g}$ 's and $\Delta C_{p}$ 's.

\begin{tabular}{|c|c|c|c|c|c|c|c|c|}
\hline & & & Stage 1 & & & Stage 2 & & \\
\hline Formulation & $\begin{array}{l}\mathrm{w}_{\mathrm{FK} /} \\
\text { TMPTA } / \mathrm{w}_{\mathrm{HT}}{ }^{\mathrm{a}} \\
(\%)\end{array}$ & $f^{b}$ & $\begin{array}{l}\text { Acrylate } \\
\text { conversion (\%) }\end{array}$ & $\begin{array}{l}T_{g} \\
\left({ }^{\circ} \mathrm{C}\right)\end{array}$ & $\begin{array}{l}\Delta C_{p}(\mathrm{~J} / \\
\mathrm{gK})\end{array}$ & $\begin{array}{l}\text { Acrylate } \\
\text { conversion (\%) }\end{array}$ & $\begin{array}{l}T_{g} \\
\left({ }^{\circ} \mathrm{C}\right)\end{array}$ & $\begin{array}{l}\Delta C_{p}(\mathrm{~J} / \\
\mathrm{gK})\end{array}$ \\
\hline KF1_TMPTA1_HT0 & 100 & 3.00 & 96 & 23 & 0.403 & 100 & 25 & 0.388 \\
\hline KF1_TMPTA1_HT1 & 63 & 2.63 & 94 & -49 & 0.465 & 100 & 36 & 0.344 \\
\hline KF1_TMPTA1_HT2 & 46 & 2.51 & 78 & -71 & 0.549 & 100 & 50 & 0.257 \\
\hline KF1_TMPTA1_HT3 & 36 & 2.44 & 74 & -79 & 0.598 & 100 & 85 & 0.241 \\
\hline KF1_TMPTA1_HT4 & 30 & 2.41 & 60 & -83 & 0.642 & 100 & 110 & 0.218 \\
\hline KF0_TMPTA0_HT1 & 0 & 2.26 & - & -95 & 0.718 & 100 & 119 & 0.198 \\
\hline
\end{tabular}

a Composition in weight ratio of FK/TMPTA (first stage)/HT(second stage).

b Functionalities determined taking into account the composition of formulations, that FK and TMPTA react completely and the following functionalities of each reactive monomer: $f_{\mathrm{KF}}=3, f_{\mathrm{TMPTA}}=3$ and $f_{\mathrm{HT}}=2.26$.

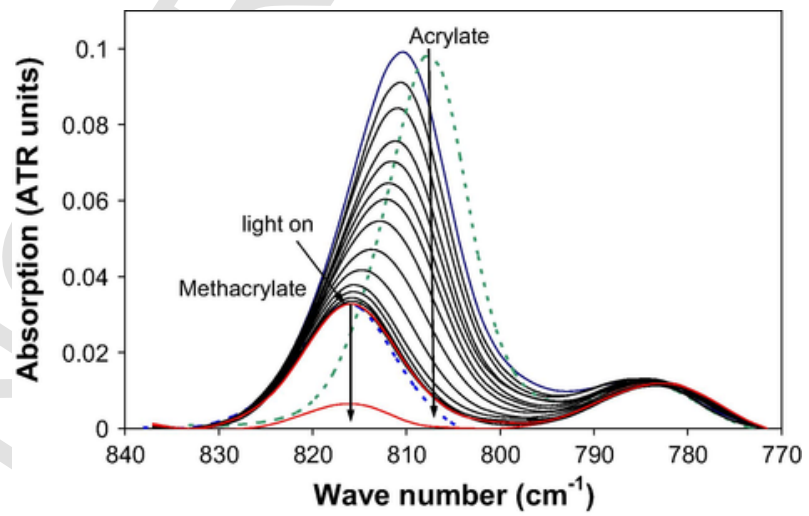

Fig. 3. Evolution of FTIR spectra at $35^{\circ} \mathrm{C}$ for KF1_TMPTA1_HT1 monitored during Michael reaction for $19 \mathrm{~h}$ (black continuous lines) and during radical photopolymerization for $5 \mathrm{~min}$ (red continuous lines). Spectra were taken every $15 \mathrm{~s}$. FTIR spectra of neat TMPTA and HT mixture were also included in green and blue dashed lines, respectively. (For interpretation of the references to colour in this figure legend, the reader is referred to the web version of this article.) 


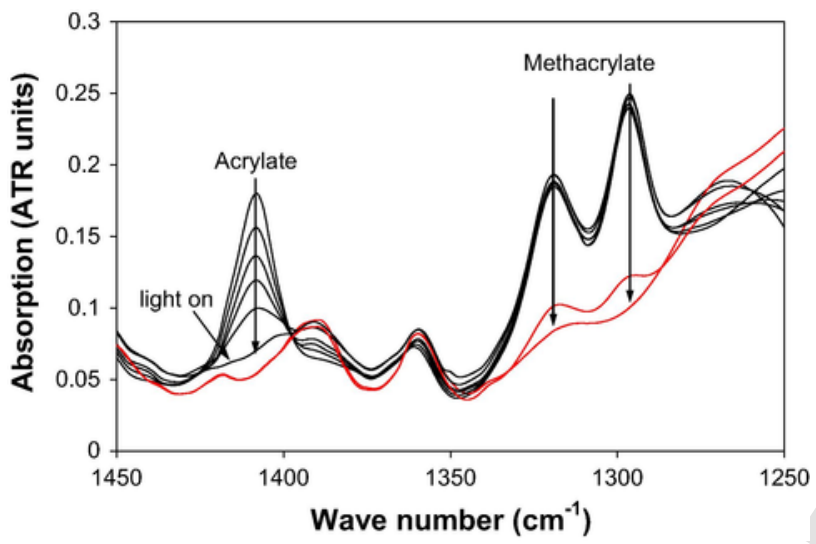

Fig. 4. Evolution of FTIR spectra at $35^{\circ} \mathrm{C}$ for KF1_TMPTA1_HT1 monitored during Michael reaction for $19 \mathrm{~h}$ (black continuous lines) and during radical photopolymerization for $5 \mathrm{~min}$ (red continuous lines). Spectra were taken every $15 \mathrm{~s}$. (For interpretation of the references to colour in this figure legend, the reader is referred to the web version of this article.)

late peaks. During the first curing stage (no UV light), acrylate groups disappeared almost completely whereas methacrylates did not react. After irradiation, both acrylates and methacrylates reacted completely. As expected, this shows that the Michael reaction is selective towards acrylates, given that methacrylates are poor Michael acceptors [15-17].

These results can be qualitatively confirmed by inspection of $1250-1450 \mathrm{~cm}^{-1}$ absorption band of the FTIR spectra shown in Fig. 4. During the first curing stage, the peak associated with acrylate groups decreases, while the methacrylate peaks remain unchanged, indicating quantitative and selective reaction of acrylate groups. Upon irradiation, both unreacted acrylate and methacrylate peaks disappear almost completely, indicating complete final conversion.

Fig. 5 compares the acrylate conversion during the first curing stage of the dual-curable formulations studied in this work. In KF1_TMPTA1_HT0 formulation (without methacrylates), acrylate groups reacted near completely in a relatively short time, confirming that acetoacetate/acrylate Michael addition took place quantitatively in the absence of methacrylates. The small amount of unreacted acrylates disappeared completely after UV-irradiation. When the weight percentage of methacrylate groups in the formulation was increased, the rate of Michael reaction dropped significantly, leading to incomplete acrylate conversion within the experimental monitoring duration. Methacrylate groups do not take part in Michael addition reaction and therefore they acted as a non-reactive diluent and slowed down the acetoacetate/acrylate reaction. This result is consistent with the fact that the rate law of acetoacetate/ acrylate Michael addition follows pseudo first-order kinetic dependence on acrylate concentration [3,23,26,27].

Increasing the temperature and/or curing time only produced a slight increase in final acrylate conversion, making the materials quite stable before UV-irradiation. It can be hypothesized that the dilution effect not only decelerates the Michael addition, but also affects the reaction equilibrium between enolate/acrylate reactants and the Michael adduct formed. Taking into account that the equilibrium constant only depends on temperature, the dilution of the reaction medium would shift the equilibrium towards the formation of enolate/acrylate monomers and consequently lower acrylate conversions would be reached after the first curing stage in methacrylate-rich formulations. Although it is accepted that click reactions, such as Michael additions are highly efficient, many authors have reported low yields depending on the type and amount of solvent

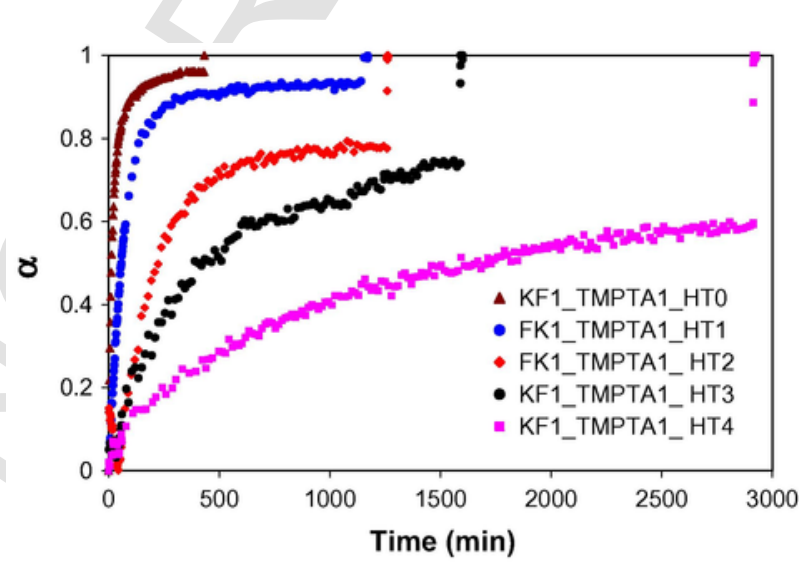

Fig. 5. Evolution of acrylate conversion of dual cured formulations by FTIR at $35^{\circ} \mathrm{C}$. The sudden change of conversion indicates when UV-irradiation and second curing stage starts. 
and reactive monomers [12,17,21,37]. A change from kinetics controlled to diffusion controlled reaction cannot be ruled out as the reason for the conversion plateau observed. Vitrification of partially cured materials cannot be responsible for low acrylate conversion reached in methacrylate-rich formulations since their $T_{g}$ 's are much lower than the curing temperature.

After the second curing stage (UV-irradiation) acrylate conversion is complete (see Fig. 5). The participation of the unreacted acrylate monomers in the second curing stage, fundamentally in methacrylate-rich formulations, is not a drawback, because it ensures there is covalent linkage between the two thermosetting networks formed and a higher homogeneity of the final material. So, the final materials are covalent semi-interpenetrating polymer networks, combining poly(keto ester) and poly(methacrylate) networks that are crosslinked to form a single polymer network.

Table 1 summarizes relevant results from the analysis of the first and second curing stages and the thermal properties of the partially- and fully-cured materials. It can be observed that the $T_{g}$ after Michael addition decreases with increasing HT content, due to the plasticizing effect of the methacrylate monomers and the presence of unreacted acrylates. Accordingly, $\Delta C_{p}$ increases with increasing HT content. For all formulations, with the exception of KF1_TMPTA1_HT0, which reacted almost completely during stage 1, a significant increase in $T_{g}$, takes place during stage 2 due to the reaction of methacrylate and unreacted acrylate groups remaining after stage 1.

The fully cured materials have increasing $T_{g}$ and decreasing $\Delta C_{p}$ with increasing HT content. The increase in $T_{g}$ and the decrease of $\Delta C_{p}$ can be related with the higher rigidity of poly(methacrylate) network in comparison with poly(keto ester), caused by the presence of a methyl group in $\alpha$ position in the methacrylate, but not with the crosslinking density, given the large amount of reactive diluent HEMA used in the methacrylate mixture. These trends are in line with previously reported results for similar click dual-curable systems [16].

The gelation during Michael reaction was studied by isothermal FTIR/TMA combined experiments at $35^{\circ} \mathrm{C}$ and the results are summarized in Table 2. All formulations gelled during the first curing stage, with increasing $t_{\text {gel }}$ on increasing methacrylate content, in accordance with the decrease in reaction rate caused by the dilution of the methacrylate on the KF/TMPTA mixture, as noted above. The gel point conversion was calculated theoretically using the Flory-Stockmayer equation (Eq. (2)), and assuming that the acetoacetate monomer has a functionality of 3 . The theoretical conversion at gelation, $\alpha_{g e l}^{\text {theor }}$, and the experimental ones, $\alpha_{g e l}^{\text {exp }}$, have similar values. This result indicates that acetoacetate-acrylate Michael addition follows a quasi ideal random step-wise reaction profile. The conversion at the gel point, $\alpha_{\text {gel }}$, is barely affected by the presence of methacrylate groups. All the mixtures contain the same KF/ TMPTA ratio and the dilution effect of methacrylate is apparently not producing any significant delay on the gel point conversion $[34,38]$. The slight differences between $\alpha_{g e l}^{\text {exp }}$ than $\alpha_{g e l}^{\text {theorl }}$ fall within the experimental error associated with the comparison of isothermal curing times determined from instruments that may have slightly different temperature calibrations.

Fig. 6 compares the $\tan \delta$ and storage moduli of final materials determined by DMA. The relaxation curves were shifted towards higher temperatures with increasing methacrylate content, indicating an increase in stiffness, in agreement with calorimetric $T_{g}$ 's shown in Table 1. It can be observed a completely different relaxation profile of the networks formed by

Table 2

Experimental gelation data $\left(\alpha_{\text {gel }}^{\text {exp }}\right.$ and $\left.t_{g e l}\right)$ obtained by isothermal FTIR/TMA combined experiments at $35^{\circ} \mathrm{C} . \alpha_{g e l}^{\text {theor }}$ obtained by using Eq. $(2)$.

\begin{tabular}{llll}
\hline Formulation & $\alpha_{\text {gel }}^{\text {theor }}$ & $\alpha_{g e l}^{\exp }$ & $t_{\text {gel }}(\mathrm{min})$ \\
\hline FK1_TMPTA1_HT0 & 0.5 & 0.55 & 22 \\
FK1_TMPTA1_HT1 & 0.5 & 0.56 & 85 \\
FK1_TMPTA1_HT2 & 0.5 & 0.53 & 228 \\
FK1_TMPTA1_HT3 & 0.5 & 0.53 & 480 \\
FK1_TMPTA1_HT4 & 0.5 & 0.51 & 1850 \\
\hline
\end{tabular}

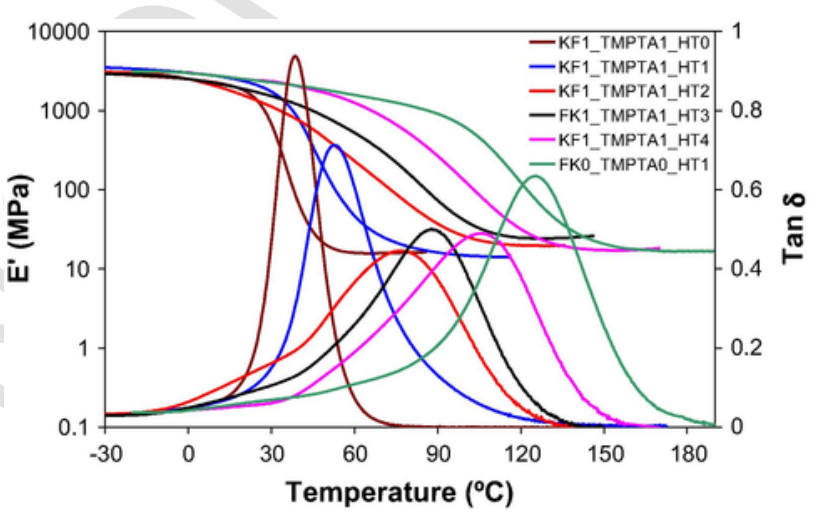

Fig. 6. Storage moduli and $\tan \delta$ curves as function of temperature of fully cured KF/TMPTA/HT formulations. 
step-growth mechanism (Michael addition, FK1_TMPTA1_HTO formulation) and chain-growth mechanism (free radical polymerization, FK0_TMPTA0_HT1 formulation). Whereas the poly(keto ester) network showed a narrow relaxation and high damping capacity (high $\tan \delta$ peak), the poly(methacrylate) network showed a wide heterogeneous relaxation and low capacity for mechanical energy absorption near its $T_{g}$ (low $\tan \delta$ peak). Accordingly, the breadth of the tan $\delta$ peaks increase on increasing the methacrylate content, as commonly observed in strong liquids resistant to breakdown well above $T_{g}$ [39]. The breadth of the relaxation curves of methacrylate-rich formulations suggests that the poly(methacrylate) part of the network has a stronger contribution to network heterogeneity in comparison to the poly(keto ester) part, consequently more homogeneous materials can be obtained from methacrylate-poor formulations.

The moduli after relaxation was in the range of $15-25 \mathrm{MPa}$, the differences were deemed insignificant, due to the similar degree of crosslinking of all formulations and to the low stiffness of the materials after relaxation of the network structure.

Fig. 7 shows the thermogravimetric curves for all formulations studied. It can be observed that the degradation took place in two steps. The first one, taking place at low temperatures, can be related with the degradation of the poly(methacrylate) network, while the second degradation step occurring at higher temperatures can be attributed to the degradation of the poly(keto ester) structure. Poly(methacrylate)s degrade at relatively low temperatures through the degradation of the hydroxyethyl pendant groups from HEMA, whereas poly(keto ester) networks degrade at higher temperature by degradation of ester groups of the network structure [12,40]. The contribution of each degradation step is approximately proportional to the methacrylate and acetoacetate/acrylate content of the formulation.

To summarize, the proposed dual curing methodology with two different reactive mechanisms, step-growth and chain-growth, leads to completely cured materials, with properties that can be easily tuned after both curing stages by simply changing of stoichiometric ratio. The thermal and mechanical properties of the material can be further tailored by changing the structure and functionality of the monomers. The materials in the intermediate stage, that are stable during prolonged periods, can be manipulated, shaped and their final form easily fixed by irradiation.

The curing process is environmentally friendly with no VOCs and energy efficient owing to the possibility of low temperature cure and UV irradiation for short periods.

\section{Conclusions}

A new family of poly(keto ester)-poly(methacrylate) thermosets was prepared via a dual-curing solvent-free process at room temperature. The first stage of curing is a self-limiting click Michael addition between acetoacetate and acrylate monomers and the second stage is a methacrylate radical photopolymerization. The selectivity of the Michael addition towards acrylates was demonstrated. This selectivity allows preparing materials with tuned intermediate and final properties, by appropriate selection of the structure of acrylates and methacrylates used and by changing the relative contribution of the two curing steps.

The versatility of the methodology and the handleability of cured products are attributed to the orthogonality of the first curing stage, since methacrylate monomers are not able to react during Michael addition at ambient temperature, and on the use of two different polymerization mechanisms, step-growth and chain-growth, which do not interfere with each other. In addition, the intermediate materials at the end of the first curing stage are highly stable, and the second curing stage can be started by UV irradiation when desired.

The strong dilution effect of methacrylates on Michael addition, leave unreacted acrylate groups after the first curing stage, which later can react by free radical mediated photopolymerization during second stage, allowing the desirable formation of covalent linkages between poly(keto ester) and poly(methacrylate)s networks.
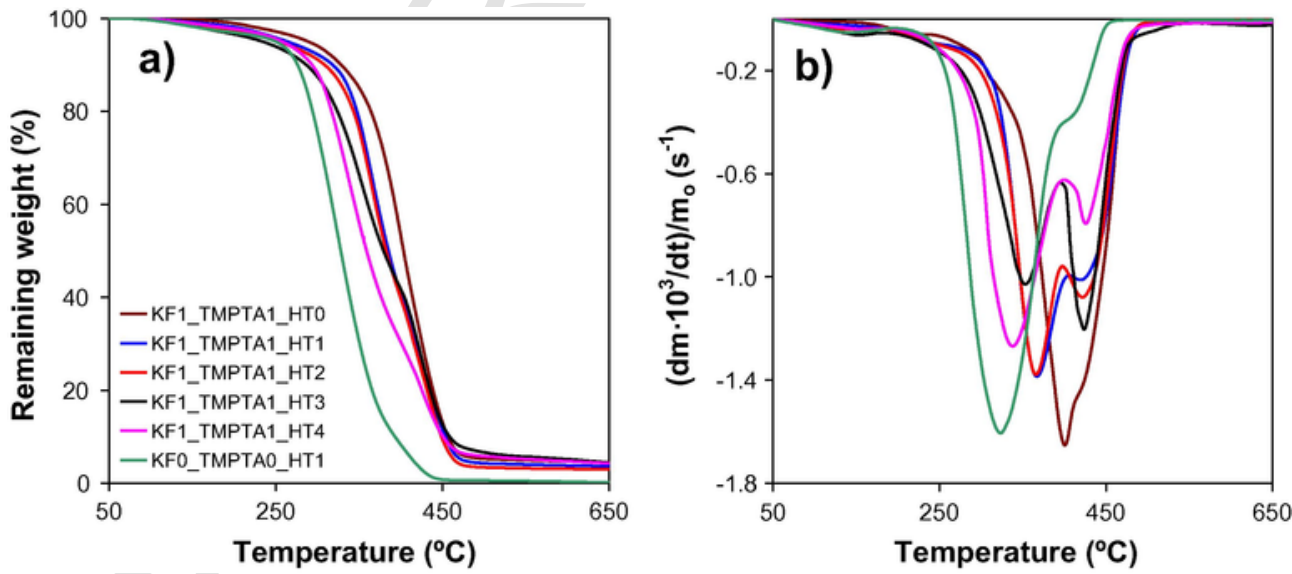

Fig. 7. Remaining weight curves (a) and rate of weight loss (b) against temperature at $10^{\circ} \mathrm{C} / \mathrm{min}$ in nitrogen atmosphere of fully cured $\mathrm{KF} / \mathrm{TMPTA} / \mathrm{HT}$ formulations. 


\section{Uncited references}

$[32,33]$.

\section{Acknowledgments}

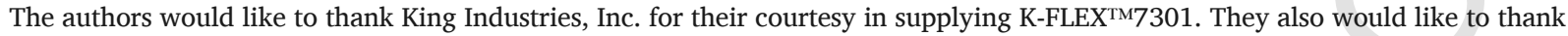
MINECO (Ministerio de Economía y Competitividad) (MAT2014-53706-C03-01 and MAT2014-53706-C03-02) and the Comissionat per a Universitats i Recerca del DIUE de la Generalitat de Catalunya (2014-SGR-67). Xavier F.-F. acknowledges the Serra Hunter programme of the Generalitat de Catalunya.

\section{Appendix A. Supplementary material}

Supplementary data associated with this article can be found, in the online version, at https://doi.org/10.1016/j.eurpolymj.2017. 11.003.

\section{References}

[1] X. Ramis, X. Fernández-Francos, S. De La Flor, F. Ferrando, A. Serra, Click-Based Dual-Curing Thermosets, in: Q. Guo, (Ed.), Thermosets: Structure, Properties and Applications, 2nd ed., Elsevier, Amsterdam, 2017 (Chapter 16).

[2] D.P. Nair, M. Podgórski, S. Chatani, T. Gong, W. Xi, C.R. Fenoli, C.N. Bowman, The thiol-michael addition click reaction: a powerful and widely used tool in materials chemistry, Chem. Mater. 26 (2014) 724-744.

[3] B.D. Mather, K. Viswanathan, K.M. Miller, T.E. Long, Michael addition reactions in macromolecular design for emerging technologies, Prog. Polym. Sci. 31 (2006) 487-531.

[4] J.W. Chan, C.E. Hoyle, A.B. Lowe, Sequential phosphine-catalyzed, nucleophilic thiol-ene/radical-mediated thiol-yne reactions and the facile orthogonal synthesis of polyfunctional materials, J. Am. Chem. Soc. 131 (2009) 5751-5753.

[5] H. Peng, D.P. Nair, B.A. Kowalski, W. Xi, T. Gong, C. Wang, M. Cole, N.B. Cramer, X. Xie, R.R. McLeod, C.N. Bowman, High performance graded rainbow holograms via two-stage sequential orthogonal thiol-click chemistry, Macromolecules 47 (2014) 2306-2315.

[6] J.A. Carioscia, J.W. Stansbury, C.N. Bowman, Evaluation and control of thiol-ene/thiol-epoxy hybrid networks, Polymer 48 (2007) $1526-1532$.

[7] J. Shin, H. Matsushima, C.M. Comer, C.N. Bowman, C.E. Hoyle, Thiol-isocyanate-ene ternary networks by sequential and simultaneous thiol click reactions, Chem. Mat. 22 (2010) 2616-2625.

[8] S. Chatani, C. Wang, M. Podgórski, C.N. Bowman, Triple shape memory materials incorporating two distinct polymer networks formed by selective thiol-Michael addition reactions, Macromolecules 47 (2014) 4949-4954.

[9] C.E. Hoyle, T.Y. Lee, T. Roper, Thiol-Enes: chemistry of the past with promise for the future, J. Polym. Sci. Part A: Polym. Chem. 42 (2004) $5301-55338$.

[10] D.P. Nair, N.B. Cramer, J.C. Gaipa, M.K. McBride, E.M. Matherly, R.R. McLeod, R. Shandas, C.N. Bowman, Two-stage reactive polymer network forming systems, Adv. Funct. Mat. 22 (2012) 1502-1510.

[11] N. Moszener, V. Rheinberger, Reaction behaviour of monomeric $\beta$-ketoesters, Macromol. Rapid Commun. 16 (1995) $135-138$.

[12] G. Gonzalez, X. Fernandez-Francos, A. Serra, M. Sangermano, X. Ramis, Environmentally-friendly processing of thermosets by two-stage sequential aza-Michael addition and free-radical polymerization of amine-acrylate mixtures, Polym. Chem. 6 (2015) 6987-6997.

[13] X. Fernández-Francos, A.O. Konuray, A. Belmonte, S. De la Flor, A. Serra, X. Ramis, Sequential curing of off-stoichiometric thiol-epoxy thermosets with a custom-tailored structure, Polym. Chem. 7 (2015) 2280-2290.

[14] M. Retailleau, A. Ibrahim, C. Croutxé-Barghorn, X. Allonas, Christian Ley, D. Le Nouen, One-pot three-step polymerization system using double click Michael addition and radical photopolymerization, ACS Macro. Lett. 4 (2015) 1327-1331.

[15] W. Xi, H. Peng, A. Aguirre-Soto, C.J. Kloxin, J.W. Stansbury, C.N. Bowman, Spatial and temporal control of thiol-Michael addition via photocaged superbase in photopatterning and two-stage polymer networks formation, Macromolecules 47 (2014) 6159-6165.

[16] A.O. Konuray, X. Fernández-Francos, À. Serra, X. Ramis, Sequential curing of amine-acrylate-methacrylate mixtures based on selective aza-Michael addition followed by radical photopolymerization, Eur. Polym. J. 84 (2016) 256-267.

[17] J. Pavlinec, N. Moszner, Photocured polymer networks based on multifunctional $\beta$-ketoesters and acrylates, J. Appl. Polym. Sci. 65 (1997) $165-178$.

[18] H. Matsushima, J. Shin, C.N. Bowman, C.E. Hoyle, Thiol-isocyanate-acrylate ternary networks by selective thiol-click chemistry, J. Polym. Sci. Part A: Polym. Chem. 48 (2010) 3255-3264.

[19] S.J. Ma, S.J. Mannino, N.J. Wagner, C.J. Kloxin, Photodirected formation and control of wrinkles on a thiol-ene elastomer, ACS Macro Lett. 2 (2013) 474-477.

[20] J.S. Witzeman, W.D. Nottingham, Transacetoacetylation with tert-butyl acetoacetate: synthetic applications, J. Org. Chem. 56 (1991) $1713-1718$.

[21] Y.-B. Kim, H.K. Kim, H. Nishida, T. Endo, Synthesis and characterization of hyperbranched Poly( $\beta$-ketoester) by the Michael addition, Macromol. Mater. Eng. 289 (2004) 923-926.

[22] A. Gigot, A. Morra, M. Castellino, C.F. Pirri, V. Mittal, K. Dietliker, M. Sangermano, Photolatent base catalyzed Michael-addition and concomitant in situ graphene oxide reduction to obtain electrically and thermally conductive UV-cured composite, Polymer 108 (2017) $251-256$.

[23] B.D. Mather, K.M. Miller, T.E. Long, Novel Michael addition networks containing poly(propylene glycol) telechelic oligomers, Macromol. Chem. Phys. 207 (2006) 1324-1333.

[24] B. Bartman, G. Swift, Acetoacetate functionalized polymers and monomers Useful for crosslinking formulations, US Patent 4,408,018, 1983.

[25] J.T. Maddox, S.J. Marsh, Acetoacetate-functional monomers and their uses in coatings compositions, WO2012082348 A1, 2012.

[26] R.J. Clemens, F. Del Rector, A comparison of catalysts for crosslinking acetoacetylated resins via the Michael reaction, J. Coat. Tech. 61 (1989) 83-91. 
[27] S.R. Williams, K.M. Miller, T.E. Long, Michael addition reaction kinetics of acetoacetate and acrylates for the formation of polymeric networks, Prog. React. Kinet. Mec. 32 (2007) 165-194.

[28] N. Pietschmann, K. Stengel, B. Hoesselbarth, Investigations into vinylogic addition reactions of modifed polyester resins, Prog. Org. Coat. 36 (1999) 64-69.

[29] A.O. Konuray, F. Liendo, X. Fernández-Francos, A. Serra, M. Sangermano, X. Ramis, Sequential curing of thiol-acetoacetate-acrylate thermosets by latent Michael addition reactions, Polymer 113 (2017) 193-199.

[30] H. Tobita, A.E. Hamielec, Control of network structure in free-radical crosslinking copolymerization, Polymer 33 (1992) $3647-3657$.

[31] J.W. Chan, C.E. Hoyle, A.B. Lowe, C.N. Bowman, Nucleophile-initiated thiol-Michael reactions: effect of organocatalyst thiol, and ene, Macromolecules 43 (2010) 6381-6388.

[32] N.B. Colthup, L.H. Daly, S.E. Wiberley, Introduction to Infrared and Raman Spectroscopy, third ed., Academic Press, San Diego, 1990.

[33] V. Kumar, Y.K. Bhardwajm, S. Sabharwal, Coating characteristics of electron beam cured bisphenol A diglycidyl ether diacrylate resin containing 1,6-hexanediol diacrylate on wood surface, Prog. Org. Coat. 55 (2006) 316-323.

[34] J.P. Pascault, H. Sautereau, J. Verdu, R.J.J. Williams, Thermosetting Polymers, Marcel Dekker, New York, 2002.

[35] J. Brandrup, E.H. Immergut, E.A. Grulke (Eds.), Polymer Handbook, fourth ed., John Wiley \& Sons Inc, New York, USA, 1999.

[36] C.-W. Huang, Y.-M. Sun, W.-F. Huang, Curing kinetics of the synthesis of poly(2-hydroxyethylmethacrylate) (PHEMA) with ethylene glycol dimethacrylate (EGDMA) as a crosslinking agent, J. Polym. Sci. Part A: Polym. Chem. 35 (1997) 1873-1889.

[37] G.-Z. Li, R.K. Randev, A.H. Soeriyadi, G. Rees, C. Boyer, Z. Tong, T.P. Davis, C.R. Becera, D.M. Haddleton, Investigation into thiol-(meth)acrylate Michael addition reactions using amine and phosphine catalysts, Polym. Chem. 1 (2010) 1196-1204.

[38] Y. Tanaka, J.L. Stanford, R. Stepto, Interpretation of gel points of an epoxy-amine system including ring formation and unequal reactivity: measurements of gel points and analyses on ring structures, Macromolecules 45 (2012) 7197-7205.

[39] A.C. Agnell, Relaxation in liquids, polymers and plastic crystals-strong/fragile patterns and problems relaxation in liquids, polymers and plastic crystals, J. Non. Cryst. Solids 131-133 (1991) 13-31.

[40] B.J. Holland, J.N. May, The kinetics and mechanisms of the thermal degradation of poly(methyl methacrylate) studied by thermal analysis-Fourier transform infrared spectroscopy, Polymer 42 (2001) 4825-4835. 